\title{
Simultaneous Determination of Matrine and Tinidazole in Compound Lotion by RH-HPLC Method
}

\author{
Zhikui Yin, ${ }^{1}$ Suying Ma, ${ }^{1}$ Jincai Wang, ${ }^{2}$ and Xiaojun Shang ${ }^{1}$ \\ ${ }^{1}$ School of Pharmacy, Xinxiang Medical University, Jin Sui Road, Xinxiang 453003, China \\ ${ }^{2}$ Department of Pharmacy, The First Affiliated Hospital of Xinxiang Medical University, Jian Kang Road, Weihui 453100, China
}

Correspondence should be addressed to Xiaojun Shang; shangxiaojun2004@163.com

Received 16 May 2013; Accepted 2 July 2013

Academic Editor: Josep Esteve-Romero

Copyright (c) 2013 Zhikui Yin et al. This is an open access article distributed under the Creative Commons Attribution License, which permits unrestricted use, distribution, and reproduction in any medium, provided the original work is properly cited.

\begin{abstract}
A simple, sensitive, and accurate RP-HPLC coupled with UV detector method was developed and validated for simultaneous determination of matrine and tinidazole in compound lotion. The chromatographic separation of the two compounds was carried out with a SinoChoom ODS-BP $C_{18}$ column $(5 \mu \mathrm{m}, 4.6 \mathrm{~mm} \times 200 \mathrm{~mm})$ analytical column, using a mobile phase consisting of $0.025 \mathrm{~mol} / \mathrm{L}$ potassium dihydrogen phosphate (containing triethylamine $0.05 \%, \mathrm{v} / \mathrm{v}$ ) and acetonitrile $(80: 20$, v/v) at a flow rate of $1.0 \mathrm{~mL} / \mathrm{min}$. The detection was monitored at 210 and $310 \mathrm{~nm}$ for matrine and tinidazole, respectively. Total run time was $12 \mathrm{~min}$, and the column was maintained at $25^{\circ} \mathrm{C}$. The excipients in the compound lotion did not interfere with the drug peaks. The calibration curves of matrine and tinidazole were fairly linear over the concentration ranges of $10.0-100.0 \mu \mathrm{g} / \mathrm{mL}(r=0.9954)$ and $20.0-$ $200.0 \mu \mathrm{g} / \mathrm{mL}(r=0.9968)$, respectively. The RSD of both the intraday and interday variations was below $1.5 \%$ for matrine and tinidazole. The proposed HPLC method was validated according to International Conference on Harmonisation and proved to be suitable for the simultaneous determination of matrine and tinidazole in compound lotion.
\end{abstract}

\section{Introduction}

Vaginosis is an inflammation of the vagina. It can result in discharge, itching, and pain and is often associated with an irritation or infection of the vulva. The infection is usually caused by Candida albicans, Gardnerella, Trichomonas vaginalis, chlamydia, and Mycoplasma. It is estimated that bacterial vaginosis is associated with a twofold increased risk of preterm birth and a sixfold increased risk of miscarriage [1]. Bacterial vaginosis is also found to be associated with an increased susceptibility to sexually transmitted infections, herpes simplex viruses, human papillomavirus, and human immunodeficiency virus $[2,3]$. It is necessary to prepare an effective preparation for prevention and treatment of vaginosis.

Sophora flavescens Ait is a leguminous plant widely distributed in the northwestern region of China. It is an important Chinese herbal remedy that has been used for thousands of years in history. The important ingredient extracted from the herbal remedy was matrine whose chemical name is
(7aS, 13aR, 13b, $13 \mathrm{cS})$-dodecahydro-1H, 5H, 10H-dipyrido $\left[2,1-f: 3^{\prime}, 2^{\prime}, 1^{\prime}-i j\right][1,6]$ naphthyridin-10-one (Figure 1) $[4,5]$. It has been officially listed in the Chinese Pharmacopoeia. Previous studies have indicated that matrine has a variety of pharmacological effects, including anti-inflammatory, anticancer, and action as a kappa opioid receptor and $\mu$-receptor agonist [6-9]. It was often used to treatment of inflammatory disease and cancer with no obvious toxicity or side effect in clinical.

Tinidazole, chemically 1-(2-ethylsulfonylethyl)-2-methyl-5-nitro-imidazole, is a second-generation 5-nitroimidazole product (Figure 1). It is widely used for treatment and prevention of many protozoan infections caused by amoeba, giardia, and trichomonas because of higher efficacy and fewer adverse effects.

The compound lotion of matrine and tinidazole can play synergy roles in the effective prevention and treatment of vaginosis diseases.

HPLC methods have been widely used to determine matrine and tinidazole in samples at present [10-19]. To our 


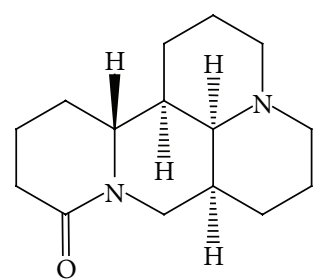

(a)

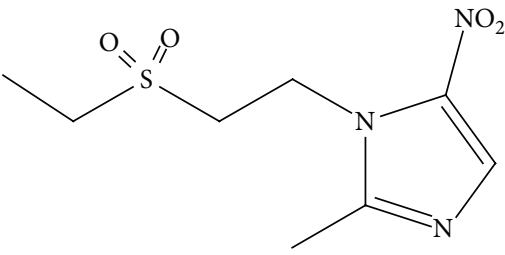

(b)

Figure 1: Chemical structures of matrine (a) and tinidazole (b).

knowledge, few HPLC methods have been developed in the literature for determination of matrine and tinidazole in lotion simultaneously. The literature was mainly focused on determination of the content of matrine and tinidazole one by one.

The aim of this study is to develop and validate a simple, rapid, sensitive, and reproducible HPLC method according to International Conference on Harmonisation to determine matrine and tinidazole simultaneously when combined in lotion with the advantages of shorter retention time and run time [20].

\section{Experiment}

2.1. Reagents and Chemicals. Tinidazole and matrine were received as gifts from Zhengzhou Yonghe Pharmaceutical Co., Ltd. (Zhengzhou, China). The two standards were of over 99.5\% purity. HPLC grade acetonitrile and other analytical grade chemicals were purchased from Xinshiji Chemicals Co., Ltd. (Xinxiang, China). The deionized water in the study was purified with Smart2 Pure 12 UV/UF purification system (Thermo Fisher Scientific, USA).

\subsection{Preparation of Matrine/Tinidazole Compound Lotion.} Matrine/tinidazole compound lotion was prepared by dissolution method. Tinidazole $(2 \mathrm{~g})$ and matrine $(1 \mathrm{~g})$ were accurately weighted into a $100 \mathrm{~mL}$ glass beaker and then by dissolved with $40 \mathrm{~mL}$ ethanol. $20 \mathrm{~mL}$ glycerin and $0.5 \mathrm{~g}$ menthol dissolved with $10 \mathrm{~mL}$ ethanol were mixed thoroughly in tinidazole/matrine ethanol solution. After mixing, the solution was made up to $1000 \mathrm{~mL}$ with water in ultrasonic bath for $10 \mathrm{~min}$, filtered, packed, and stored in the refrigerator at $4^{\circ} \mathrm{C}$ for further use.

2.3. Liquid Chromatographic Conditions. The liquid chromatographic analyses were performed using a Shimadzu system that is comprised of an LC-20AT pump, SPD 20A UV-visible absorbance detector connected to Shimadzu Spin Chrome software. Chromatographic separation was achieved on a reversed-phase ODS-BP $\mathrm{C}_{18}$ column $(5 \mu \mathrm{m}, 4.6 \mathrm{~mm} \times$ $200 \mathrm{~mm}$ ). An injection volume of $20 \mu \mathrm{L}$ was optimized in method via a Rheodyne syringe.

The mobile phase under isocratic mode was a mixture of acetonitrile-triethylamine $(0.05 \%)$ in $0.025 \mathrm{~mol} / \mathrm{L}$ potassium dihydrogen phosphate $(20: 80, \mathrm{v} / \mathrm{v})$. The mobile phase was degassed by an ultrasonic bath and filtered through a $0.45 \mu \mathrm{m}$ membrane filter under vacuum. The eluents were detected at
$210 \mathrm{~nm}$ from $0 \mathrm{~min}$ to $7.0 \mathrm{~min}$ and at $310 \mathrm{~nm}$ from $7.0 \mathrm{~min}$ to $12.0 \mathrm{~min}$. The flow rate was $1.0 \mathrm{~mL} / \mathrm{min}$. All determinations were performed at ambient temperature $25^{\circ} \mathrm{C}$.

2.4. Preparation of Standard Stock Solutions and Working Solutions. Stock standard solutions were prepared with mobile phase separately to give a final concentration of $1.0 \mathrm{mg} / \mathrm{mL}$ for tinidazole and matrine. The combined standard solutions were prepared with the previous two solutions. Intermediate and working solutions were prepared by diluting stock solutions with the mobile phase. Calibration standard solutions were prepared in the concentration range of 10.0 to $100.0 \mu \mathrm{g} / \mathrm{mL}$ for matrine and 20.0 to $200.0 \mu \mathrm{g} / \mathrm{mL}$ for tinidazole and injected into the system in triplicate. The chromatogram peak area of each drug concentration was calculated. The regression of the drug concentration versus the peak area was obtained.

2.5. Quantification of Tinidazole and Matrine in Compound Lotion. One $\mathrm{mL}$ compound lotion was accurately transferred into a $10 \mathrm{~mL}$ volumetric flask and made up to volume with mobile phase. The solution was diluted appropriately to yield concentrations of matrine $(50.0 \mu \mathrm{g} / \mathrm{mL})$ and tinidazole $(100.0 \mu \mathrm{g} / \mathrm{mL})$. A $20 \mu \mathrm{L}$ aliquot of the sample solution was injected into the chromatographic system three times under optimized chromatographic conditions. The peak area was measured at $210 \mathrm{~nm}$ from $0 \mathrm{~min}$ to $7.0 \mathrm{~min}$ and at $310 \mathrm{~nm}$ from $7.0 \mathrm{~min}$ to $12.0 \mathrm{~min}$ for matrine and tinidazole, respectively. Drug concentrations of the samples were determined by interpolation from calibration plots of each drug previously obtained.

2.6. Method Validation. The method was validated in terms of parameters of specificity, linearity, sensitivity, accuracy, precision, and reproducibility according to International Conference on Harmonisation.

The specificity of the method was demonstrated by comparing chromatograms of combined working solution (matrine $50.0 \mu \mathrm{g} / \mathrm{mL}$ and tinidazole $100.0 \mu \mathrm{g} / \mathrm{mL}$ ), blank excipients sample without matrine and tinidazole, and equal concentrations samples of compound lotion made with the previous procedure. All the samples were analyzed and recorded to ensure the absence of interfering peaks.

The linearity of the method was evaluated with matrine and tinidazole working solutions at eight different concentrations. The concentration was $10.0-100.0 \mu \mathrm{g} / \mathrm{mL}$ for matrine and $20.0-200.0 \mu \mathrm{g} / \mathrm{mL}$ for tinidazole, respectively. All the 


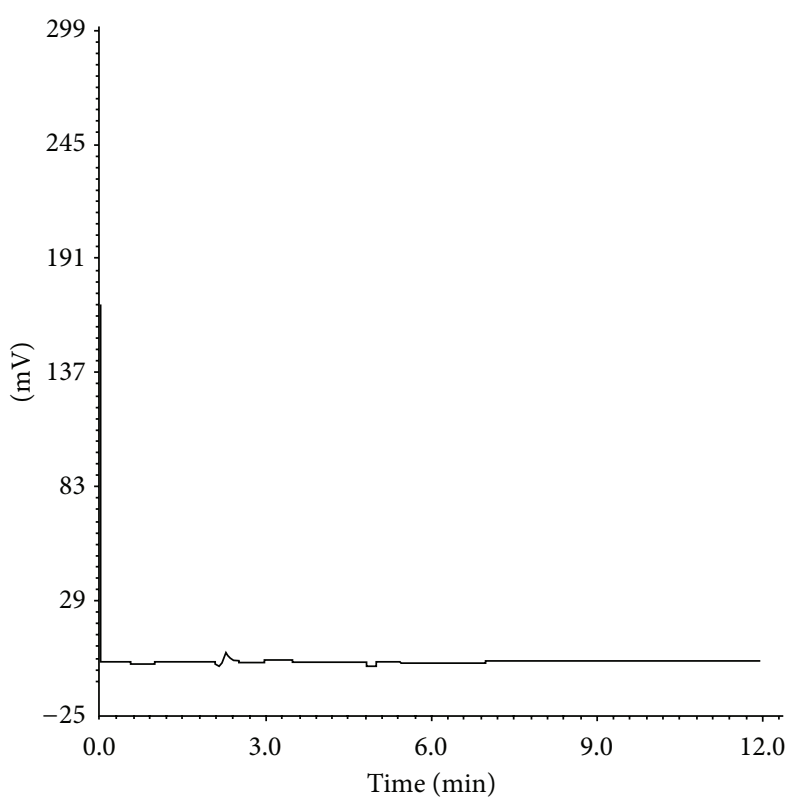

(a)

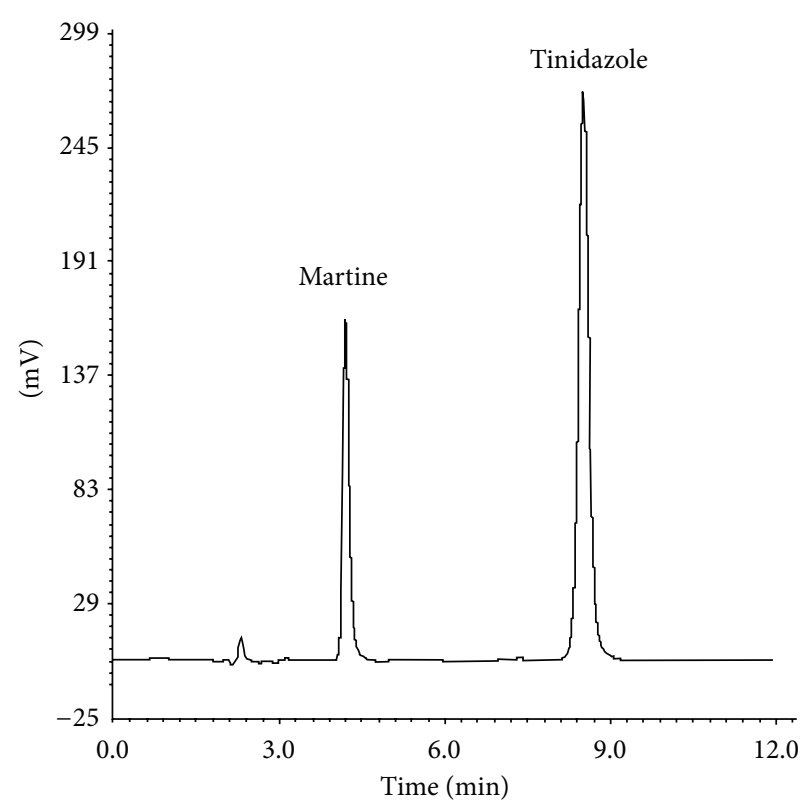

(b)

FIgURE 2: Typical HPLC chromatograms of (a) blank excipients sample and (b) compound lotion sample with matrine $(50.0 \mu \mathrm{g} / \mathrm{mL})$ and tinidazole $(100.0 \mu \mathrm{g} / \mathrm{mL})$.

samples prepared for linearity were injected into chromatographic system $(n=3)$. The responses were measured as peak area.

The sensitivity of the method was tested with limit of detection (LOD) and limit of quantification (LOQ). The LOD and LOQ were expressed as the analyte concentration which generates a signal corresponding to three and ten standard deviations, respectively, above the mean blank signal.

The accuracy of the method was assessed by comparing the percent analyte recovered by the proposed method at three concentration levels (matrine 40.0, 50.0, and $60.0 \mu \mathrm{g}$ / $\mathrm{mL}$ and tinidazole $80.0,100.0$, and $120.0 \mu \mathrm{g} / \mathrm{mL}$ ).

The precision of the method was checked by repeatability of injection, repeatability (intraday), intermediate precision (interday), and reproducibility. Injection repeatability was studied by calculating percent relative standard deviation (\% RSD) for ten determinations each of peak area of matrine $(50.0 \mu \mathrm{g} / \mathrm{mL})$ and tinidazole $(100.0 \mu \mathrm{g} / \mathrm{mL})$ performed on the same day. The same solutions were injected in triplicate for both intraday and interday variations.

\section{Results}

3.1. Method Validation. The specificity was evaluated by analyzing blank excipients sample, combined working solution (matrine $50.0 \mu \mathrm{g} / \mathrm{mL}$, and tinidazole $100.0 \mu \mathrm{g} / \mathrm{mL}$ ), and equal concentrations samples of compound lotion. From the UVvisible spectra, matrine had maximum absorption at $210 \mathrm{~nm}$ and tinidazole had maximum absorption at $310 \mathrm{~nm}$. Thus, $210 \mathrm{~nm}$ and $310 \mathrm{~nm}$ were selected as detection wavelengths. The typical HPLC chromatograms under optimum conditions were shown in Figure 2. The retention times of matrine and tinidazole at a flow rate of $1.0 \mathrm{~mL} / \mathrm{min}$ were $4.90 \mathrm{~min}$ and
$8.60 \mathrm{~min}$, respectively. Analyte peaks were well resolved and free from tailing ( $<1.5$ for both analytes). The excipients in the compound lotion did not interfere with the detection of matrine and tinidazole.

The calibration curves obtained by plotting peak area against concentration were linear over the concentration range of $10.0-100.0 \mu \mathrm{g} / \mathrm{mL}$ for matrine and $20.0-200.0 \mu \mathrm{g} / \mathrm{mL}$ for tinidazole at eight different concentrations, respectively. The correlation coefficient values were over 0.9950. Typical regression equations were calculated as follows: $y=28.27 x+$ 25.08 for matrine and $y=33.99 x+134.7$ for tinidazole, where $y$ is peak area based on three parallel measurements and $x$ is the concentration $(\mu \mathrm{g} / \mathrm{mL})$ of matrine or tinidazole standard solution. The correlation coefficients indicate a good linear relationship between peak area and concentration over a wide range.

Under the developed HPLC conditions, the LOD for matrine and tinidazole was 0.5 and $0.2 \mu \mathrm{g} / \mathrm{mL}$, respectively, which is the concentration that yields an S/N of 3, while LOQ was 1.0 and $0.5 \mu \mathrm{g} / \mathrm{mL}$, respectively.

Mean recovery for matrine and tinidazole was $100.18 \pm$ $0.65 \%$ and $99.92 \pm 0.88 \%$, respectively. The intra- and interday RSD values were lower than $1.5 \%$. The low values of RSD revealed satisfactory precision and accuracy of this present method. Reproducibility was checked by having the samples analyzed by another analyst using the same instrument and the same laboratory. There was no significant difference between the RSD values indicating that the proposed method was reproducible.

3.2. Content of Matrine and Tinidazole in Compound Lotion. Matrine and tinidazole were simultaneously determined with the proposed method in compound lotion. The results of the 
assay yielded $100.13 \pm 0.53 \%$ for matrine and $99.86 \pm 0.47 \%$ for tinidazole indicating that the method was selective and accurate for the simultaneous determination of matrine and tinidazole without interference from the excipients in the compound lotion dosage form.

\section{Discussion}

This study was essentially focused on the simultaneous determination of coformulated matrine and tinidazole in compound lotion. Glycerol in the formulation can form film that could protect the skin. Menthol is not only used to reduce the pain stimulus, but it also promotes the penetration of the drug. Further study will be published in another research paper later.

Matrine and tinidazole were soluble in organic solvents including methanol and acetonitrile. The use of mobile phase as extraction reagent provided minimal impurities and better separation.

Several mobile phase systems including methanol, acetonitrile, and buffer solutions of different proportions have been tested in this study. A mixture of acetonitrile-triethylamine $(0.05 \%)$ in $0.025 \mathrm{~mol} / \mathrm{L}$ potassium dihydrogen phosphate $(20: 80, \mathrm{v} / \mathrm{v})$ under the isocratic elution system with a flow rate of $1.0 \mathrm{~mL} / \mathrm{min}$ was selected as the optimum mobile phase for baseline separation, symmetrical peak, and shorter retention time. A UV detector was set at $210 \mathrm{~nm}$ for matrine and $310 \mathrm{~nm}$ for tinidazole. Under these conditions, elution of analytes was completed in less than $12.0 \mathrm{~min}$. Retention times of matrine and tinidazole were $4.90 \mathrm{~min}$ and $8.60 \mathrm{~min}$, respectively. The chromatograms were evaluated on the basis of peak areas of the two analytes.

The method was validated according to ICH guidelines with the parameters of specificity, linearity, sensitivity, accuracy, precision, and reproducibility. The resolved analyte peaks without tailing between matrine and tinidazole showed the efficiency of the method to identify and determine each analyte at the same time with no interference. The accuracy, sensitivity, precision, and reproducibility data show that the method is accurate within the desired ranges.

\section{Conclusion}

A simple, rapid, selective, and sensitive HPLC method has been developed and validated for the simultaneous determination of matrine and tinidazole when coformulated in compound lotion. The method will be helpful for simultaneous determination of matrine and tinidazole in compound lotion and can be reliably used by almost every drug laboratory.

\section{Conflict of Interests}

The authors declare that they have no conflict of interests.

\section{Acknowledgment}

The authors would like to acknowledge the financial support provided by the Education Department of Henan Province (Foundation no. 13A350851).

\section{References}

[1] G. G. Donders, K. Van Calsteren, G. Bellen et al., "Predictive value for preterm birth of abnormal vaginal flora, bacterial vaginosis and aerobic vaginitis during the first trimester of pregnancy," An International Journal of Obstetrics and Gynaecology, vol. 116, no. 10, pp. 1315-1324, 2009.

[2] J. E. Allsworth, V. A. Lewis, and J. F. Peipert, "Viral sexually transmitted infections and bacterial vaginosis: 2001-2004 national health and nutrition examination survey data," Sexually Transmitted Diseases, vol. 35, no. 9, pp. 791-796, 2008.

[3] R. M. Brotman, M. A. Klebanoff, T. R. Nansel et al., "Bacterial vaginosis assessed by Gram stain and diminished colonization resistance to incident gonococcal, chlamydial, and trichomonal genital infection," Journal of Infectious Diseases, vol. 202, no. 12, pp. 1907-1915, 2010.

[4] Matrine[homepage on the Internet], State Food and Drug Administration, http://www.sda.gov.cn/bzzzmd/bkl.htm.

[5] X. Han, X. Liu, J. Nie et al., "The preparation of matrine sustained release tablet and the determination of its dissolution rate," Chinese Traditional Patent Medicine, no. 3, pp. 365-368, 2008.

[6] Y. Zhang, H. Zhang, P. Yu et al., "Effects of matrine against the growth of human lung cancer and hepatoma cells as well as lung cancer cell migration," Cytotechnology, vol. 59, no. 3, pp. 191200, 2009.

[7] P. Xiao, H. Kubo, M. Ohsawa et al., "Kappa-opioid receptormediated antinociceptive effects of stereoisomers and derivatives of (+)-matrine in mice," Planta Medica, vol. 65, no. 3, pp. 230-233, 1999.

[8] K. Higashiyama, Y. Takeuchi, T. Yamauchi et al., "Implication of the descending dynorphinergic neuron projecting to the spinal cord in the $(+)$-matrine- and $(+)$-allomatrine-induced antinociceptive effects," Biological and Pharmaceutical Bulletin, vol. 28, no. 5, pp. 845-848, 2005.

[9] A. Xue and W. Song, "Survey studies on pharmacological effects of matrine," Tianjin Pharmacy, vol. 5, pp. 62-64, 2010.

[10] Y. Q. Wang, P. P. Zhang, N. L. Jiang et al., "Simultaneous quantification of metronidazole, tinidazole, ornidazole and morinidazole in human saliva," Journal of Chromatography B, vol. 899, pp. 27-30, 2012.

[11] J. O. Boison, P. A. Asea, and J. L. Matus, "Validation of a new screening, determinative, and confirmatory multi-residue method for nitroimidazoles and their hydroxy metabolites in turkey muscle tissue by liquid chromatography-tandem mass spectrometry," Drug Testing and Analysis, vol. 4, supplement 1, pp. 130-138, 2012.

[12] L. Y. Wu, J. F. Liu, Y. H. Zhang et al., "Development of a HPLC/MS/MS method for simultaneous determination of tinidazole, dyclonine and chlorhexidine in rat plasma and its application in the pharmacokinetic research of a film-forming solution," Journal of Pharmaceutical and Biomedical Analysis, vol. 62, pp. 224-227, 2012.

[13] Y. Zhang, X. Huang, Z. Jiang et al., "Simultaneous determination of metacavir and its metabolites in rat plasma using highperformance liquid chromatography with tandem mass spectrometric detection (LC-MS/MS)," Biomedical Chromatography, vol. 26, no. 3, pp. 363-370, 2012.

[14] Y. Bi, F. Hu, S. Feng et al., "Simultaneous determination of five active components in compound preparation of Dangguishuan by high-performance liquid chromatography," Zhongguo Zhongyao Zazhi, vol. 35, no. 18, pp. 2402-2405, 2010. 
[15] Z. Yang, S. Gao, T. Yin et al., "Biopharmaceutical and pharmacokinetic characterization of matrine as determined by a sensitive and robust UPLC-MS/MS method," Journal of Pharmaceutical and Biomedical Analysis, vol. 51, no. 5, pp. 1120-1127, 2010.

[16] X.-L. Zhang, H.-R. Xu, W.-L. Chen et al., "Matrine determination and pharmacokinetics in human plasma using LC/MS/ MS," Journal of Chromatography B, vol. 877, no. 27, pp. 32533256, 2009.

[17] J. Sun, J. Mao, X. Liu et al., "Separation and mechanism elucidation for six structure-like Matrine-type alkaloids by micellar liquid chromatography," Journal of Separation Science, vol. 32, no. 12, pp. 2043-2050, 2009.

[18] H. Zheng, G. Chen, L. Shi et al., "Determination of oxymatrine and its metabolite matrine in rat blood and dermal microdialysates by high throughput liquid chromatography/tandem mass spectrometry," Journal of Pharmaceutical and Biomedical Analysis, vol. 49, no. 2, pp. 427-433, 2009.

[19] L. Zhang, Z.-W. Wang, J.-W. Lian et al., "Simultaneous determination of matrine, oxysophocarpin and oxymatrine in rat plasma by HPLC-MS and its application in the pharmacokinetic study," Yaoxue Xuebao, vol. 43, no. 8, pp. 843-847, 2008.

[20] “Text on validation of analytical procedures Q2A," in Proceedings of the International Conference on Harmonisation of Technical Requirements for Registration of Pharmaceuticals for Human Use, London, UK, 1994. 

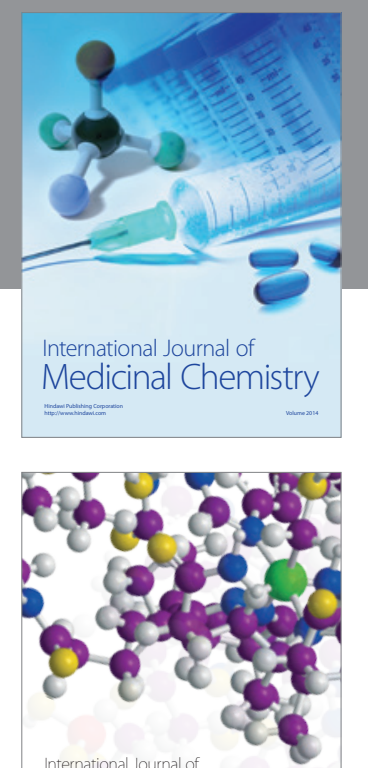

\section{Carbohydrate} Chemistry

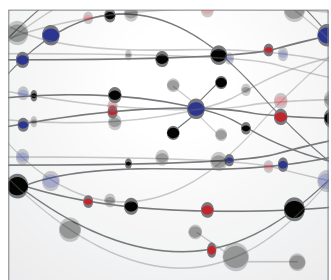

The Scientific World Journal
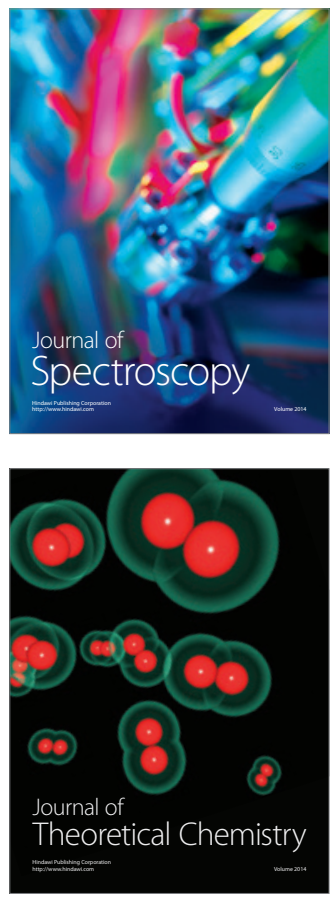
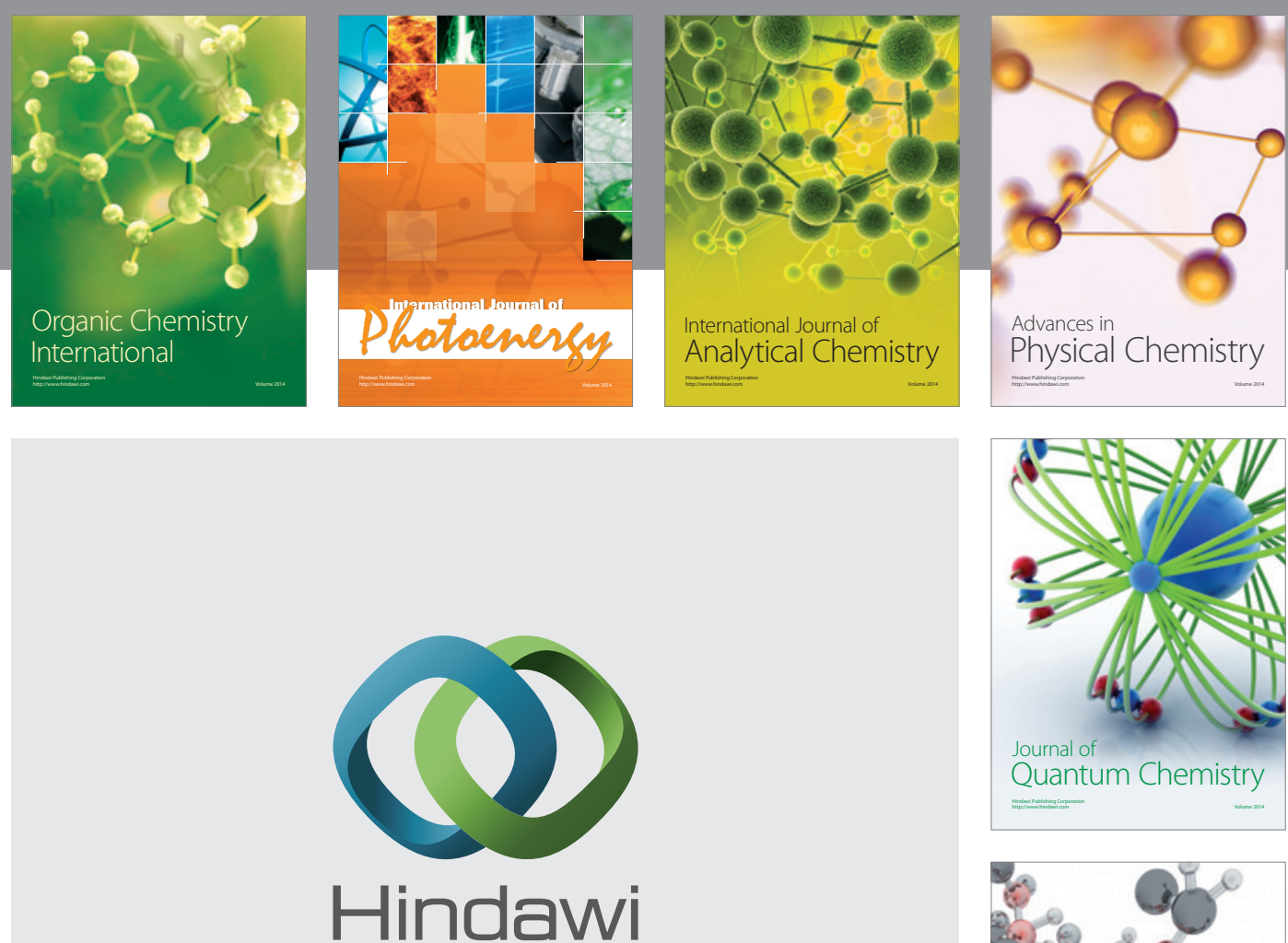

Submit your manuscripts at

http://www.hindawi.com

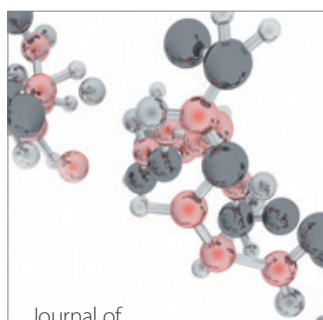

Analytical Methods

in Chemistry

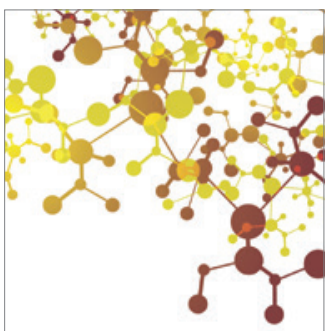

Journal of

Applied Chemistry

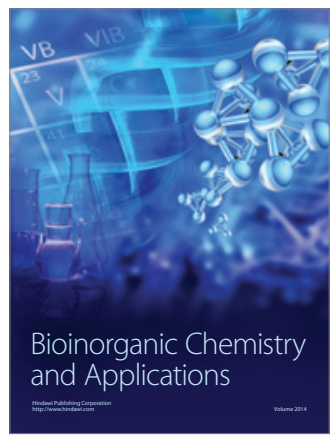

Inorganic Chemistry
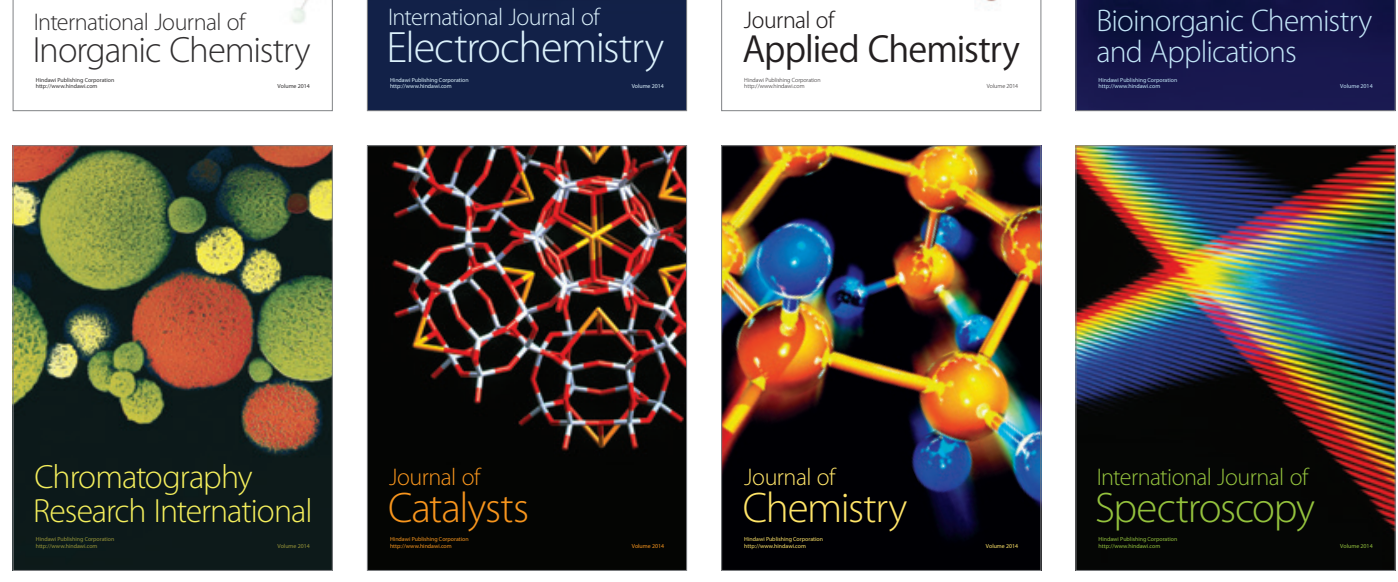